\title{
EDITORIAL
}

\section{Schizophrenia and violence ${ }^{1}$}

Violence in schizophrenic patients is a major concern of their families, fellow patients, treating personnel, and the public at large. It is not clear how many schizophrenics are violent; estimates range from $8 \%$ (Fottrell, 1980) to $45 \%$ of patients (Shader et al. 1977). These estimates vary depending on the definition and detection of violence, diagnostic criteria for schizophrenia, concomitant mental disorders, patient selection, and patient setting. In addition to these factors, there may be genuine differences among levels of schizophrenic (and other) violence in different cultures : European studies generally tend to report a lower incidence of violence than the American ones, and unsystematic observations by visiting foreign psychiatrists suggest that patient violence appears to be rare in China and Japan.

\section{VIOLENT BEHAVIOUR IN THE CONTEXT OF SCHIZOPHRENIC SYMPTOMATOLOGY}

Examination of schizophrenic patients who had committed violent crimes revealed that a very large majority of them had been psychotic at the time of the offence (Planansky \& Johnston, 1977; Taylor, 1985). However, Virkkunen (1974) reported that only about one third of violent offences by schizophrenics are committed during a psychotic episode. Differences in patient selection may account for this discrepancy; Virkkunen gives no diagnostic criteria for schizophrenia in his 1974 paper. Different symptomatologies may help delineate different subgroups of violent patients or types of violent behaviour. Certain violent patients, termed 'high visibility' patients, engaged in verbal threats, while others, the 'low visibility' patients (all schizophrenic or schizoaffective) did not demonstrate any precursory verbal assault. These subgroups differed from one another with respect to psychopathology characteristics. The former scored particularly high on the hostile-suspiciousness factor of the Brief Psychiatric Rating Scale (BPRS), while the latter scored particularly high on the withdrawal-retardation factor of that scale (Tanke \& Yesavage, 1985). The type of violence may also vary as a function of the symptomatology. Delusions, especially paranoid ones, are prominent among symptoms accompanying violent offence. The violence that ensues from such delusions, such as in paranoid schizophrenia, is usually well planned, directed at a significant individual in the patient's life, and often dangerous. In contrast to this, violence which occurs in the context of disorganized psychotic states, such as in undifferentiated schizophrenia, is less focused and often less dangerous (Krakowski et al. 1986).

Somewhat surprisingly, command hallucinations seem to play a relatively minor role in most violent offences by psychotics (Taylor, 1985; Hellerstein et al. 1987). Other symptoms, such as delusional misidentification, have been reported to be associated with violence (De Pauw \& Szulecka, 1988).

Special attention should be paid to the time at which the violence occurs in the course of the illness: prior to hospitalization, early or late during hospitalization (Krakowski et al. 1986). Such a distinction will help explain seemingly discrepant findings as to which diagnostic group or subgroup is more violent as well as which symptoms accompany violence. Usually, it is in acutely psychotic recently admitted schizophrenics that violence is associated with conceptual disorganization, hallucination and unusual though content (Yesavage et al. 1981). Such distinction is also helpful with regard to subtypes of schizophrenia.

\footnotetext{
${ }^{1}$ Address for correspondence: Dr J. Volavka, Nathan S. Kline Institute for Psychiatric Research, Orangeburg, NY 10962, USA.
} 
Subtypes of schizophrenia have been repeatedly studied in relationship to violence, and most studies dichotomize the patients into paranoid and non-paranoid groups. Five studies found paranoid schizophrenics to be more violent than non-paranoid ones (Blackburn, 1968; Planansky \& Johnston, 1977; Tardiff \& Sweillam, 1980; Addad et al. 1981: Rossi et al. 1986); two studies reported the opposite (Shader et al. 1977; Tardiff \& Sweillam, 1982), and one study found no difference between these subtypes (Yesavage, 1983). These apparently disparate findings can be synthesized and explained on the basis of the differences in time at which assessments were made. Studies reporting more violence in paranoid patients focused on acute patients, whereas studies reporting the opposite results focused on chronic in-patients who had been in the hospital for a long time. The study, which found no difference between the two subtypes, investigated violence in patients who spent an intermediate amount of time in the hospital. These variations in the prevalence of violence may reflect different response to treatment of the subtype: paranoid schizophrenics are more violent while psychotic, but they respond to treatment faster and remit more thoroughly than the other subtypes. Relations between psychopathology and violence were reviewed elsewhere in greater detail (Krakowski et al. 1986).

\section{CAUSES AND MANAGEMENT OF VIOLENCE IN SCHIZOPHRENICS}

Violence results from interactions between the patient and his environment. We feel that the presence of certain predisposing factors, current psychopathology, and environmental factors will co-determine whether an assault or another violent act will occur. This statement seems rather obvious, but it is not self-evident, and surprisingly little research has been done to test such multiple interactions. Typically, the studies report either some characteristics of the patients involved in violence, or some environmental features conducive to violence.

The causes and management of violence in recently admitted, acutely psychotic patients are somewhat easier to study than those occurring in more chronic schizophrenics. Violence in these acute patients appears to be closely linked to their current psychopathology, and it subsides within the first several weeks as the psychosis improves with neuroleptic treatment. Thiothixene plasma levels are inversely related to patients' assaultiveness during this early post-admission period (Yesavage, 1982).

However, not all schizophrenic violence subsides within several weeks after the admission to the hospital (or after the start of neuroleptic treatment). Certain patients continue to be assaultive in the hospital in spite of apparently adequate neuroleptic treatment. Many hospitals have a special unit for the management of such persistently violent patients; such units are generally better staffed, patients have more space there, and programmes and rules provide a more structured environment than is available in the rest of the hospital. In our experience, approximately $50 \%$ of persistently violent schizophrenic patients transferred to such a unit responded to this environmental change by refraining from further assaults (Krakowski et al. 1988). The remaining $50 \%$ (the 'nonresponders') continued to be assaultive on this specialized unit. This lack of response persisted in spite of neuroleptic treatment using relatively high dosages. The schizophrenic 'non-responders' differed from the 'responders' mostly in demonstrating higher neurological impairment. The violent patients ('responders' and 'non-responders' alike) reported a history of arrest and conviction for violent crime much more frequently than non-violent (control) patients. Presence of neurological impairment has been reported in other violent subjects who do not have schizophrenia, such as homicidally aggressive young children (Lewis et al. 1983), violent juvenile delinquents (Lewis et al. 1979) and adult death row inmates (Lewis et al. 1988). Thus neurological impairment is an important factor predisposing to violence. However, it remains to be better delineated in all these different groups of patients; in schizophrenics, its relation to the illness must be defined. It is unlikely that this impairment will be similar in all these different patients.

Some of the aggressive schizophrenic patients who fail to respond to neuroleptics and environmental change may respond to lithium, but the evidence for this is not very convincing (Sheard, 1985). Carbamazepine in combination with neuroleptics may reduce aggression in 
schizophrenics who exhibit EEG abnormalities (Neppe, 1981), and also in those who do not (Luchins, 1984). Propranolol and other beta-adrenergic blockers may also exhibit antiaggressive effects in schizophrenics (Sorgi et al. 1986). Tryptophan alone (Morand et al. 1983) or in combination with trazodone (O'Neill et al. 1986) was reported to have some antiaggressive effects; however, in our hands tryptophan seems ineffective (Volavka, unpublished data).

None of these experimental treatments are expected to be effective in all, or even in most, cases of chronically violent schizophrenic patients. However, responding subgroups of such patients may be defined in the future, and we may learn something about underlying causes of this syndrome in the process. Serotonergic mechanisms may be involved in aggression in schizophrenics; such an involvement has been inferred for impulsive aggression against others (and self) from the low concentrations in cerebrospinal fluid (CSF) of 5-hydroxyindoleacetic acid (5-HIAA), a serotonin metabolite, in violent offenders with personality disorders (Linnoila et al. 1983). Psychopharmacological action of certain drugs could be explained on the basis of their effect on serotonin: both lithium and propranolol increase serotonergic functioning, and tryptophan of course is the serotonin precursor. Since low CSF 5-HIAA has been reported in impulsive suicide attempts (in addition to aggression against others) it is noteworthy that the assaultive 'non-responders' in our special ward reported past suicide attempts in over $50 \%$ of the cases (Krakowski et al. 1988). Other biochemical subtypes such as adrenergic (Sorgi et al. 1987), dopaminergic, or endorphinergic among violent schizophrenics are of course possible.

Table 1. Two hypothetical types of violent behaviour in schizophrenic patients

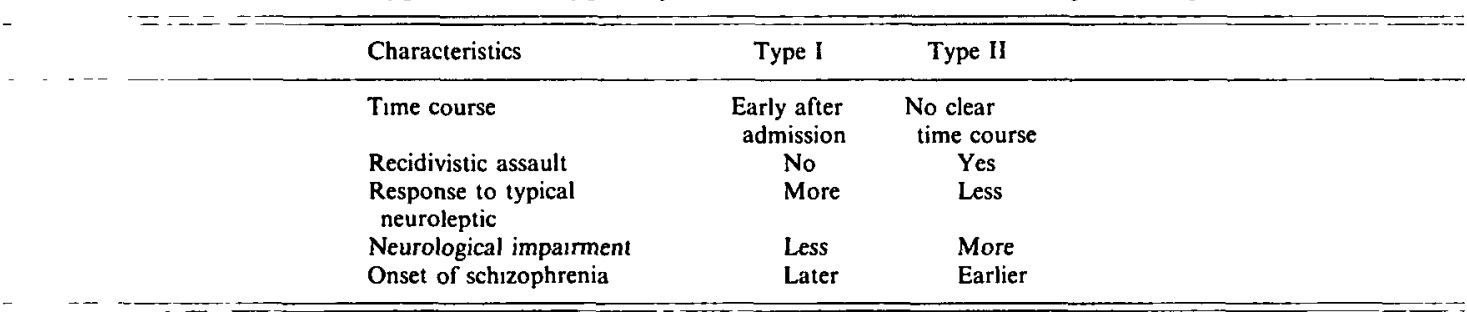

\section{FUTURE RESEARCH}

On the basis of the literature and our observations, we hypothesize at least two major types of violent behaviour in schizophrenic patients; these are schematized in Table 1. Type I would correspond to the patients studied by Yesavage and his co-workers (Yesavage et al. 1981; Yesavage, 1982). Type II remains a major challenge for clinical psychiatry. It may represent a more severe type of schizophrenia with an earlier age of onset (Krakowski et al. 1988); it probably consists of an agglomeration of subtypes which can perhaps be defined biochemically (the CSF monoamine metabolite study is an example of this approach), pharmacologically (by response to probes and treatments), neuropsychiatrically, anatomically and functionally (using CAT and PET scans). Another approach is represented by very careful studies of immediate antecedents and circumstances of assaults using video recordings (Brizer et al. 1988). We believe that the most sucessful projects will be those using multidimensional approaches to study the complex phenomenon of violence in schizophrenia. 


\section{REFERENCES}

Addad, M., Bezenech, M. \& Bourgeois, M. (1981). Criminal acts among schizophrenics in French mental hospitals. Journal of Nervous and Mental Disease 169, 289-293.

Blackburn, R (1968). Emotionality, extraversion, and non-paranoid schizophrenic offenders. British Journal of Psychiatry 115, 13011302.

Brizer, D. A., Crowner, M. L., Convit, A. \& Volavka, J. (1988). Videotape recording of inpatient assaults: a pilot study. American Journal of Psychairy 145, 751-752.

De Pauw, K. W. \& Szulecka, K. (1988). Dangerous delusions. Violence and the misindentification syndromes. Brttish Journal of Psychiatry 152, 91-96.

Fottrell, E. (1980). A study of violent behaviour among patients in psychiatric hospitals. Britsh Journal of Psychiarry 136, 216-221.

Hellerstein, D., Frosch, W. \& Koenigsberg, H. W. (1987). The clinical significance of command hallucinations. American Journal of Psychiarry 144, 219-221.

Krakowskı, M., Volavka, J. \& Brizer, D. (1986). Psychopathology and violence: a review of literature. Comprehensive Psychatry 27, 131-148.

Krakowski, M., Convit, A. \& Volavka, J. (1988). Patterns of inpatient assaultiveness. effect of neurological imparment and deviant family environment on response to treatment. Neuropsychatry. Neuropsychology and Behavioral Neurology 1, 21-29.

Lewis, D. O., Shanok, S S., Pincus, J. H. \& Glazer, G. H. (1979). Violent juvenile delinquents: psychiatric, neurological, psychological and abuse factors. Journal of the American Academy of Child Psychiatry 18, 307-319.

Lewis, D. O., Shanok, S. S., Grant, I. M. \& Ritvo, E. (1983). Homicidally aggressive young children: neuropsychatric and experiential correlates. American Journal of Psychatry 140, 148-153.

Lewis, D. O., Pincus, J. H., Bard, B., Richardson, E., Prichep, L. S., Feldman, M. \& Yeager, C. (1988). Neuropsychiatric, psychoeducational, and family characteristics of 14 juveniles condemned to death in the United States. American Journal of Psychatry 145, 584-589.

Linnoila, M., Virkkunen, M., Scheının, M., Nuutila, A., Rimon, R \& Goodwin, F D. (1983). Low cerebrospinal fluid 5-hydroxy. indoleacetic acid concentration differentiates impulsive from nonimpulsive violent behavior. Life Sciences 33, 2609-2614.

Luchins, D. J. (1984). Carbamazepine in psychiatric syndromes: clinical and neuropharmacological properties. Psychopharmacology Bulletin 20, 569-571.
Morland, C., Young, S. N. \& Ervin, F. R. (1983). Clinical response of aggressive schizophrenics to oral tryptophan. Biological Psy. chiatry 18, 575-578.

Neppe, V. M. (1981). Carbamazepıne as adjunctive treatment in nonepileptic chronic inpatients with EEG temporal lobe abnormalities. Journal of Clinical Psychiarry 44, 326-331.

O'Neil, M., Page, N., Adkins, W. N. \& Eichelman, B. (1986). Tryptophan-trazodone treatment of aggressive behaviour. Lancet $11,859-860$

Planansky, K. \& Johnston, R. (1977). Homicidal aggression in schizophrenic men. Acta Psychiatrica Scandinavica 55, 65-73.

Rossi, A. M., Jacobs, M., Monteleone, M., Olsen, R., Surber, R. W., Winkler, E. M. \& Wommack, A. (1986). Characteristics of psychiatric patients who engage in assaultive or other fearinducing behaviors. Journal of Nervous and Mental Disease 174, $154-160$.

Shader, R. J., Jackson, A. H., Harmatz, J. S. \& Applebaum, P. S. (1977). Patterns of violent behavior among schizophrenic inpatients. Diseases of the Nervous System 38, 13-16.

Sheard, M. D. (1985). Review: clinical pharmacology of aggressive behavior. Clinical Neuropharmacology 7, 173183.

Sorgi, P. J., Ratey, J. J. \& Polakoff, S. (1986). $\beta$-adrenergic blockers for the control of aggressive behaviors in patients with chronic schizophrenla. American Journal of Psychiatry 143, 775-776.

Sorgi, P. J., Ratey, J. J. \& Polakoff, S. (1987). $\beta$-adrenergic blockers for aggressive behavior in schizophrenia (letter). American Journal of Psychiatry 144, 539.

Tanke, E. D. \& Yesavage, J. A. (1985). Characteristics of assaultive patients who do and do not provide visible cues of potential violence. American Journal of Psychiatry 142, 1409-1413.

Tardiff, K. \& Sweillam, A. (1980). Assault, suicide and mental illness. Archues of General Psychiatry 37, 164-169.

Tardiff, K. \& Sweillam, A. (1982). Assaultive behavior among chronic inpatients. American Journal of Psychiatry 139, 212215.

Taylor, P. J. (1985). Motives for offending among violent and psychotic men. British Journal of Psychialry 147, 491-498.

Virkkunen, M. (1974). Observations of violence in schizophrenia. Acla Psychiatrica Scandinavica 50, 145 -151.

Yesavage, J. A. (1983). Inpatient violence and the schizophrenic patient. Acta Psychiatrica Scandinavica 67, 353.357.

Yesavage, J. A. (1982). Inpatient violence and the schizophrenic patuent: an inverse correlation between danger-related events and neuroleptuc levels Biological Psychiarry 17, 13311337.

Yesavage, J. A., Werner, P D., Becker, J., Holman, C. \& Mills, M. (1981). Inpattent evaluation of aggression in psychiatric patients. Journal of Nervous and Mental Disease 169, 299-302. 